\title{
Analysis of structure and properties of DVB-GMA based porous polymers
}

\author{
M. Sobiesiak ${ }^{1}$ (I)
}

Received: 27 November 2018 / Revised: 12 December 2018 / Accepted: 15 December 2018 / Published online: 28 December 2018 (c) The Author(s) 2018

\begin{abstract}
Polar porous polymeric microspheres divinylbenzene-glycidyl methacrylate (DVB-GMA) were synthesized with a suspension method. Two kinds of polymers differing in chemical composition and physical properties were obtained. The molar ratios of monomers in the polymers were 50:50 and 75:25, respectively. Next, the prepared materials were chemically treated with phosphoric or sulphuric acid in order to additionally modify their surface. Consequently, the polymers gained acidic character and cation exchange properties. The prepared materials were characterized by: elemental analysis, ATR-FTIR, DSC, low temperature nitrogen sorption and SPE experiments. CHN and ATR-FTIR confirmed the chemical structures of the polymers. The DSC analyses revealed their network was highly cross-linked. Porous structure parameters of the studied materials strongly depended on their chemical composition. All the materials were mesoporous with bimodal pore size distribution (3.7 nm and 5.5-7.5 nm). Highly cross-linked DVB-GMA 75:25 and its acidic derivatives had twice higher specific surface areas $\left(320-370 \mathrm{~m}^{2} / \mathrm{g}\right)$ than their less cross-linked counterparts DVB-GMA 50:50 $\left(140-190 \mathrm{~m}^{2} / \mathrm{g}\right)$. The prepared materials were tested for the sorption of phenolic compounds (phenol, 2-chlorophenol, 2,4-dichlorophenol and 2,4,6-trichlorophenol) and popular pharmaceuticals-aspirin, paracetamol and ibuprofen. The process of dynamic sorption of phenols depended on both porous structure and surface chemistry of the polymers. And the less polar character of the polymeric surface was balanced by its higher porosity to maintain the sorption ability on the same level. In case of pharmaceuticals dependence of sorption properties on porosity and/or surface chemistry was more diversified and additionally chemical nature of adsorbate had to be taken into account.
\end{abstract}

Keywords Ibuprofen $\cdot$ Phenolic compounds $\cdot$ Polymeric sorbents $\cdot$ Modification of polymers $\cdot$ Water purification

\section{Introduction}

Very intensive technical and industrial development besides many benefits brings also threats to the natural environment in the form of pollution. Governments around the world strive to replace old technologies with new ones, so called "clean" or "green" supporting environmentally friendly and environmentally responsible actions. Unfortunately, there are still many fields where adverse effects for environment

Electronic supplementary material The online version of this article (https://doi.org/10.1007/s10450-018-9998-2) contains supplementary material, which is available to authorized users.

M. Sobiesiak

magdalena.sobiesiak@umcs.pl

1 Department of Polymer Chemistry, Faculty of Chemistry, Maria Curie-Skłodowska University, M. Curie-Skłodowskiej Sq. 5, 20-031 Lublin, Poland are difficult or even impossible to eliminate. People are used to living in the world of ubiquitous chemistry. They utilize it in daily life often without awareness of its harmful effects. Consequently, chemicals such as e.g. products for cleaning or plant protection, paints or dyes are released into the environment in large amounts. Even personal care products and pharmaceuticals which are used to protect our health or to treat diseases get into the environment as a mixture of still biologically active parent compound and its metabolites. Some of these substances are considered as particularly toxic. Therefore, directives on maximum limit values of such compounds for drinking, natural and wastewater have been introduced (Fawell 1988; Keith and Telliard 1979; Parlament Europejski 2001, 2006; The European Parliament 2001; WHO 1971).

The necessity of continuous monitoring of pollutants lead to the development of techniques for their quantitative isolation from natural samples (Lucas et al. 2018). Very popular 
are analytical techniques like: solid phase extraction (SPE), solid phase microextraction (SPME), head space-solid phase microextraction (HS-SPME), and membrane technology (Namieśnik 2003). These methods are based on the phenomenon of reversible adsorption of analytes. Thanks to that the devices can be used repeatedly and meet the requirements of green analytical chemistry.

In many cases isolation of polluting compounds is not an easy task due to their polar character and low concentration. The effectiveness of the extraction equipment guarantees an adsorbent with properly selected parameters of chemical and porous structure, which determine the suitability and range of application to a particular type of analytes. Sometimes, to obtain the desired results, the usage of mixed sorbents is necessary (Simpson 2000; Hennion 1999).

Another solution can be improvement of existing or synthesis of new adsorbents. Probably the most dynamically developing group of sorbents are polymers. They have a number of advantages: thermal stability, chemical resistance in a wide range of $\mathrm{pH}$, possibility of regeneration, as well as chemical or physical modification. Important feature is also the possibility to receive the designed shape e.g. a monolith or microspheres of a certain size (Gokmen and Prez 2012; Maciejewska 2015a; Xu et al. 2008; Inagaki et al. 2010) or ordered porous structure (Gokmen and Prez 2012; Choma et al. 2009).

In this work, the synthesis of porous polymers with ester and epoxide groups is presented. The materials were prepared by polymerization of divinylbenzene-glycidyl methacrylate (DVB-GMA) using 50:50 and 75:25 monomer ratios. The materials differed from each other in term of the contents of polar functional groups and degree of crosslinking. The presence of reactive epoxide ring allowed to modify the polymeric surface by the addition of sulphuric or phosphoric acid. The right course of syntheses and modification of the prepared materials were confirmed by elemental and ATR-FTIR analyses. To describe their thermal behavior DSC studies were performed. The influence of chemical composition of the polymers and the acid modifications on porosity and sorption properties towards phenolic compounds and commonly used medicines were demonstrated. The properties of DVB-GMA copolymers were compared with those of apolar polidivinylbenzene (pDVB) and polar poli(bismaleimide-glycidyl methacrylate) (BM-GMA).

\section{Experimental}

\subsection{Chemicals and reagents}

Glycidyl methacrylate (GMA) was from Fluka AG (Buchs, Switzerland). 1,1'-(methylenedi-4,1-phenylene)bismaleimide (BM) was from Aldrich (Steinheim, Germany)
Divinylbenzene (DVB), $\alpha, \alpha^{\prime}$-azoiso-bis-butyronitrile (AIBN), poli(vinyl alcohol) (PVA), methanol (MeOH), 2-chlorophenol (ChP), 2,4-dichlorophenol (DChP) and 2,4,6-trichlorophenol (TChP), 1,4-dioxane and farmaceuticals (S)-(+)-2-(4-isobutylphenyl)propionic acid (ibuprofen), 4-acetamidophenol (paracetamol), 2-acetoxybenzoic acid (aspirin) were purchased from Merck (Darmstadt, Germany). $98 \% \mathrm{H}_{2} \mathrm{SO}_{4}, 85 \% \mathrm{H}_{3} \mathrm{PO}_{4}, 36 \% \mathrm{HCl}, \mathrm{NaOH}$, hexane, acetone, toluene and phenol (PH) were bought from $\mathrm{POCh}$ (Gliwice, Poland).

\subsection{Synthesis of polymeric microspheres}

The syntheses were carried out in a three-necked flask equipped with a stirrer, a thermometer and a water condenser. First the dispersion medium was prepared through the dissolution of $5 \mathrm{~g}$ PVA in distilled water $\left(175 \mathrm{~cm}^{3}\right)$. Next, the mixture of monomer/monomers (DVB, GMA, BM), pore forming diluent (toluene) and the initiator (AIBN) was prepared and poured to the dispersion medium, all details are collected in Table 1 . The reaction mixture was stirred at $250 \mathrm{rpm}$ for $18 \mathrm{~h}$ at $80{ }^{\circ} \mathrm{C}$ (Maciejewska 2015b). The obtained copolymers were washed in an ultrasonic bath successively with distilled water, methanol, hexane and again methanol (each solvent for half an hour). Before changing the washing solvent, the polymers were filtered off and dried. Next, the purified polymers were divided into three parts (one for further studies and two for chemical modifications).

\subsection{Modification by addition of $\mathrm{H}_{2} \mathrm{SO}_{4}$ or $\mathrm{H}_{3} \mathrm{PO}_{4}$}

In a reaction flask with a water condenser $5 \mathrm{~g}$ of the polymer, $10 \mathrm{~cm}^{3}$ of aqueous solution of $\mathrm{H}_{2} \mathrm{SO}_{4}(1: 1 \mathrm{v} / \mathrm{v})$ and $50 \mathrm{~cm}^{3}$ of dioxane were placed. The reaction was initially carried out at room temperature, after $2 \mathrm{~h}$ the mixture was heated to $60^{\circ} \mathrm{C}$, the final temperature was maintained for $4 \mathrm{~h}$. The modified polymers were filtered off and washed with aqueous solution of acetone $(1: 1 \mathrm{v} / \mathrm{v})$ to obtain a neutral $\mathrm{pH}$.

An analogous modification process was carried out with phosphoric acid, with the difference that undiluted $\mathrm{H}_{3} \mathrm{PO}_{4}$ was used in this reaction.

Table 1 Experimental parameters of the syntheses

\begin{tabular}{|c|c|c|c|c|c|}
\hline \multirow[t]{2}{*}{ Copolymer } & \multicolumn{3}{|c|}{ Monomers (g) } & \multirow{2}{*}{$\begin{array}{l}\text { Pore forming } \\
\text { diluent }\left(\mathrm{cm}^{3}\right) \\
\text { Toluene }\end{array}$} & \multirow{2}{*}{$\begin{array}{l}\text { Initiator }(\mathrm{g}) \\
\text { AIBN }\end{array}$} \\
\hline & DVB & GMA & BM & & \\
\hline $\begin{array}{l}\text { DVB-GMA } \\
50: 50\end{array}$ & 7.50 & 8.18 & & 21 & 0.2085 \\
\hline $\begin{array}{l}\text { DVB-GMA } \\
75: 25\end{array}$ & 4.10 & 11.25 & & 20.5 & 0.2039 \\
\hline BM-GMA 50:50 & & 4.09 & 10.33 & 20.5 & 0.2040 \\
\hline pDVB & 14 & & & 21 & 0.186 \\
\hline
\end{tabular}




\subsection{Characterization}

Elemental analyses were made on a Perkin Elmer CHN 2400 analyser (Palo Alto, CA, USA).

Acid numbers were determined by titrating the polymeric samples $(100 \mathrm{mg})$ with methanol solution $0.05 \mathrm{M} \mathrm{NaOH}$, using 2-3 drops of phenolphthalein as an indicator. The samples were suspended in methanol $(10 \mathrm{~mL})$. The equation is in supplementary material.

To determine epoxide numbers polymeric samples $(200 \mathrm{mg}$ ) were suspended in $25 \mathrm{~mL}$ of 1,4-dioxane solution of $\mathrm{HCl}(0.2 \mathrm{M})$ and left for $30 \mathrm{~min}$. Next, an indicatorcresol red (6-8 drops) was added and the excess of $\mathrm{HCl}$ was titrated with $0.2 \mathrm{M}$ methanol solution of $\mathrm{NaOH}$ to the purple color. The blank test was performed in the same way. The equation is in supplement.

ATR-FTIR spectra were obtained using a Bruker FTIR spectrophotometer TENSOR 27 in the frequency range of 4000 to $600 \mathrm{~cm}^{-1}$, and the resolution of the apparatus was $4 \mathrm{~cm}^{-1}$.

The porous structure of the studied sorbents was characterized by nitrogen adsorption-desorption isotherms measured at $-196{ }^{\circ} \mathrm{C}$ using adsorption analyser ASAP 2405 (Micrometrics Inc., USA). Before analyses, the samples were outgassed at $140{ }^{\circ} \mathrm{C}$ for $1 \mathrm{~h}$. The specific surface area was calculated using the standard BET method while the total pore volume was calculated as the volume of liquid adsorbate at a relative pressure of 0.99 . The pore size distributions were calculated from the desorption branch of the nitrogen isotherm using the Barrett-Joyner-Halenda (BJH) method.

DSC analyses were carried out on a Netzsch DSC 204 calorimeter (Netzsch, Germany). Samples of about $7 \mathrm{mg}$ weight were placed in an aluminum pan with a pierced lid and heated to $500{ }^{\circ} \mathrm{C}$ at a heating rate of $10{ }^{\circ} \mathrm{C} \mathrm{min}^{-1}$. The measurements were conducted under argon atmosphere. An empty pan was used as a reference.

In order to investigate sorption properties of the prepared materials, laboratory cartridges filled with $100 \mathrm{mg}$ of the studied polymer were constructed. Next, the following solutions consisting of ibuprofen $\left(100 \mathrm{mg} \mathrm{L}^{-1}\right)$, paracetamol (100 $\left.\mathrm{mg} \mathrm{L}^{-1}\right)$, aspirin $\left(100 \mathrm{mg} \mathrm{L}^{-1}\right)$ and a mixture of phenols (phenol (PH), 2-chlorophenol (ChP), 2,4-dichlorophenol (DChP), and 2,4,6-trichlorophenol (TChP) - $100 \mathrm{mg} \mathrm{L}^{-1}$ of each compound) were prepared. The procedures of sorption experiments and HPLC analyses for phenolic compounds were described in detail in previous works (Sobiesiak and Podkoscielna 2010; Sobiesiak 2011; Podkościelna et al. 2015). The sorption of pharmaceuticals was performed in the same way as for phenols. The only difference regarded parameters of HPLC analysis: a mobile phase methanol-water $(80: 20, \mathrm{v} / \mathrm{v})$, a flow rate of $1 \mathrm{~mL} \mathrm{~min}^{-1}$, detection of ibuprofen and paracetamol was performed at $222 \mathrm{~nm}$, and aspirin at $200.5 \mathrm{~nm}$, respectively.

\section{Results and discussion}

\subsection{Syntheses of the research materials and characteristics of their chemical properties}

Porous polymeric microspheres were synthesized using a suspension method. Two basic materials, with moderately polar chemical character, were prepared by polymerization of divinylbenzene and glycidyl methacrylate (DVB-GMA) with the molar ratios of monomers 50:50 and 75:25, respectively. For comparison purposes, also more polar polymer bismaleimide-glycidyl methacrylate (BM-GMA) 50:50 and apolar poli(divinylbenzene) (pDVB) were prepared. Schemes of polymerization are presented in Fig. 1.

Fig. 1 Schemes of polymerization DVB with GMA (upper equation) and BM with GMA (lower equation)
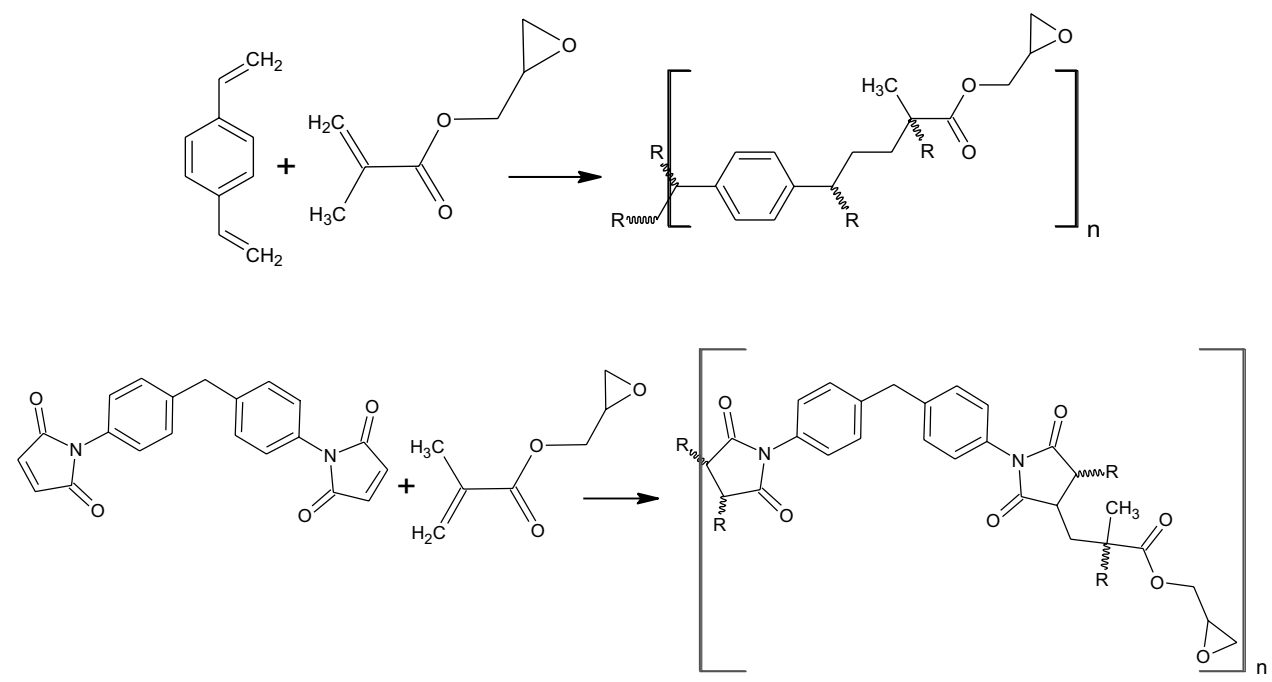
The number of polar functional groups in the constitutional unit of the polymer can be used to compare polar character of the polymer. In the pDVB, DVB-GMA 75:25, DVB-GMA 50:50, BM-GMA series, the numbers of polar groups are $0,1,2$ and 4 , respectively. Other parameter related to the quantity of polar functionalities is the percentage contents of "others" elements in elemental analysis.

In the next step, both basic polymers were modified by addition of sulfuric or phosphoric acids. The reaction runs according to epoxy-ring opening mechanism (Fig. 2) (Gorzynski Smith 2011). The acid addition proceeds quantitatively as long as the spatial structure of the polymer allows it.

As a result, four polymers differing in chemical composition and type of functional groups were obtained. In case of the unmodified polymers, the results of the elemental analyses were in good agreement with the theoretical values (Table 2) confirming the assumed course of the syntheses. Additionally, greater than zero values of the epoxide and acid numbers prove that epoxide groups remained intact in the polymeric structure and will be ready for further chemical reactions.
For the acid modified materials theoretical values were calculated assuming that one acid molecule combines with one constitutional unit of the polymer (epoxy ring). The experimental results for other elements such as $\mathrm{O}, \mathrm{S}$ and $\mathrm{P}$ are almost half lower than the theoretical ones. If the epoxide number is zero it means that some of acid molecules reacted with two epoxide rings, creating additional linkages between polymeric chains, which strengthen and stabilize the structure. For the same reasons acid numbers are not as high as one might expect. Their values in the range of $10-19 \mathrm{mg} / \mathrm{g}$ indicate the polymers gained acidic character and cation exchange properties.

Chemical structure of the prepared polymers and the presence of the introduced functional groups were also confirmed by ATR-FTIR spectra (Figs. 3, 4).

In the spectra of DVB-GMA polymers bands characteristic for the ester bonds $\left(1726,1200-1100 \mathrm{~cm}^{-1}\right)$, epoxide ring $\left(907 \mathrm{~cm}^{-1}\right)$, aromatic system $(1600-1450$, $709 \mathrm{~cm}^{-1}$ ) and aliphatic chains (2930, 1440-1480 $\left.\mathrm{cm}^{-1}\right)$ can be observed. Their intensities vary depending on the GMA content in the polymer. The signal characteristic for

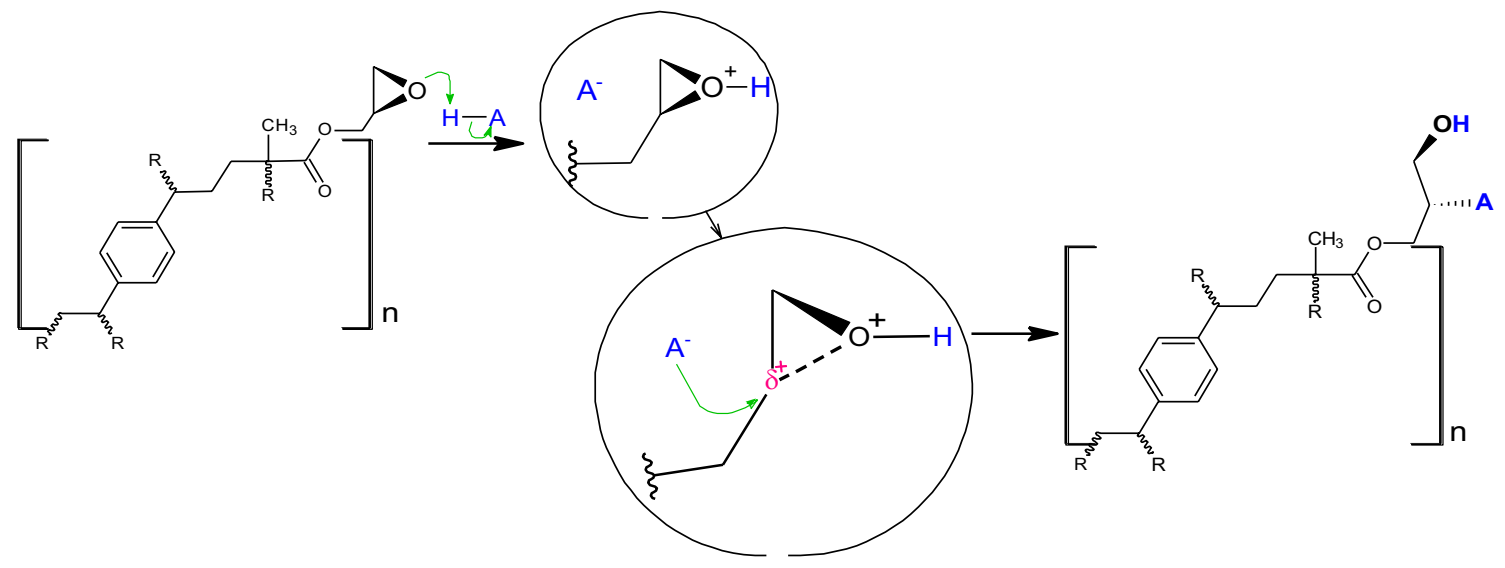

Fig. 2 Mechanism of an acid (H-A) addition to the epoxy group

Table 2 Results of elemental analysis and values of characteristic numbers (epoxide and acid)

\begin{tabular}{|c|c|c|c|c|c|c|}
\hline Material & $\begin{array}{l}\% \mathrm{C} \\
\text { (calc.) }\end{array}$ & $\begin{array}{l}\% \mathrm{H} \\
\text { (calc.) }\end{array}$ & $\begin{array}{l}\% \mathrm{~N} \\
\text { (calc.) }\end{array}$ & $\begin{array}{l}\% \text { others } \\
\text { (calc.) }\end{array}$ & $\begin{array}{l}\text { Epoxide number } \\
{[\mathrm{mol} / 100 \mathrm{~g}]}\end{array}$ & $\begin{array}{l}\text { Acid number } \\
{[\mathrm{mg} / \mathrm{g}]}\end{array}$ \\
\hline DVB-GMA 50:50 & $74.12(74.20)$ & $7.79(7.74)$ & $0.42(-)$ & $17.67(18.14)$ & 0.24 & 1.63 \\
\hline DVB-GMA $50: 50+\mathrm{H}_{2} \mathrm{SO}_{4}$ & $67.16(52.31)$ & $7.92(5.85)$ & $0.15(-)$ & $24.77(41.83)$ & 0 & 16.57 \\
\hline DVB-GMA 50:50+ $\mathrm{H}_{3} \mathrm{PO}_{4}$ & $70.61(52.33)$ & $7.84(6.15)$ & $0.20(-)$ & $21.35(41.53)$ & 0 & 18.56 \\
\hline DVB-GMA 75:25 & $81.18(83.04)$ & $7.97(7.74)$ & $0.26(-)$ & $10.59(9.22)$ & 0.17 & 3.46 \\
\hline DVB-GMA $75: 25+\mathrm{H}_{2} \mathrm{SO}_{4}$ & $78.01(69.51)$ & $8.14(6.67)$ & $0.21(-)$ & $13.64(23.82)$ & 0 & 10.69 \\
\hline DVB-GMA $75: 25+\mathrm{H}_{3} \mathrm{PO}_{4}$ & $80.38(69.52)$ & $8.02(6.83)$ & $0.26(-)$ & $11.34(23.64)$ & 0 & 18.56 \\
\hline BM-GMA 50:50 & $65.79(66.39)$ & $5.02(4.95)$ & $5.40(5.73)$ & $23.79(22.93)$ & 0.15 & 1.76 \\
\hline $\mathrm{pDVB}$ & $89.2(92.62)$ & $8.17(7.74)$ & $0.48(-)$ & $2.15(-)$ & 0 & 0 \\
\hline
\end{tabular}


Fig. 3 ATR-FTIR spectra of unmodified polymers
Fig. 4 ATR-FTIR spectra of acid modified polymers
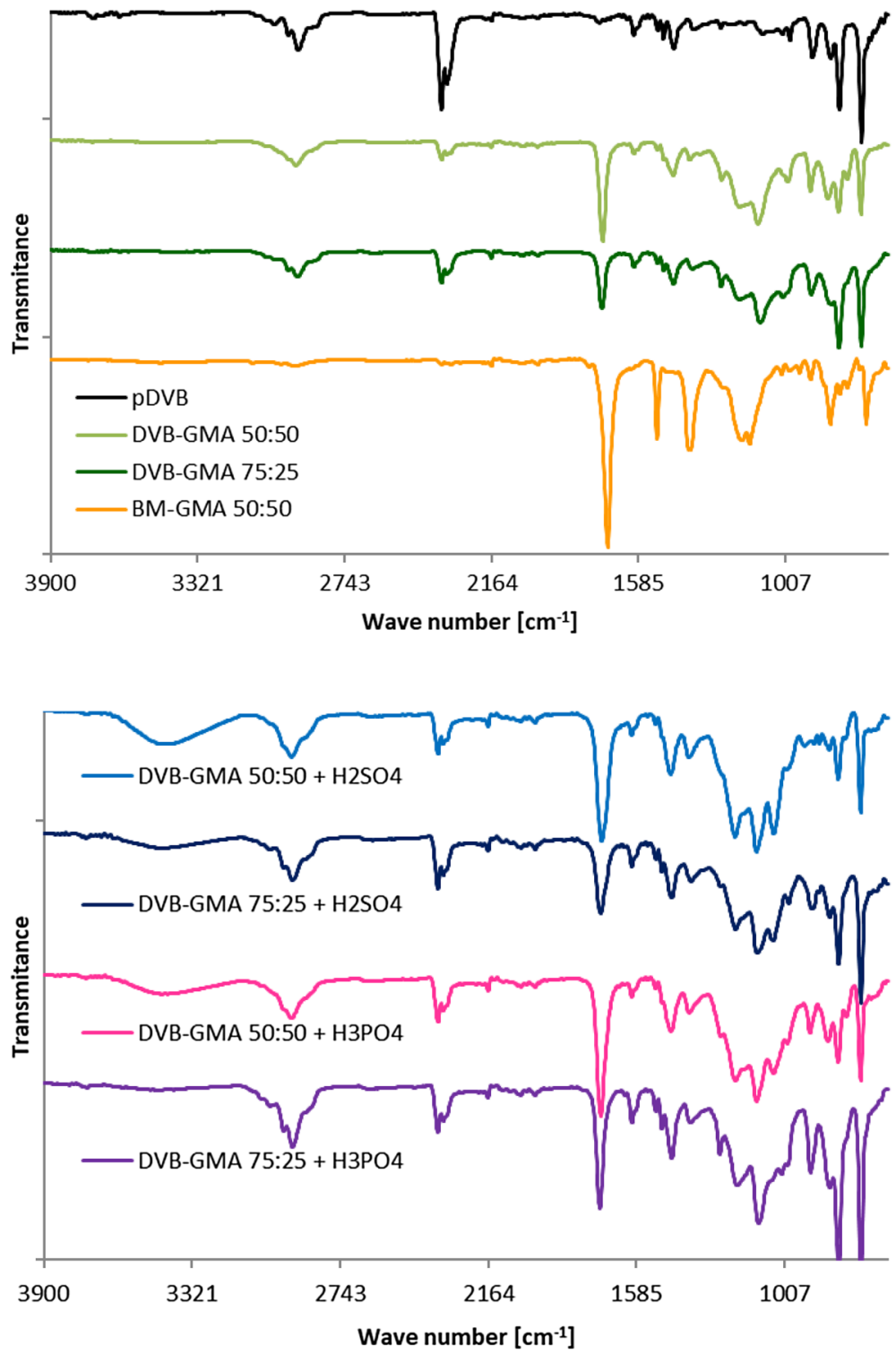

vinyl group $\left(965 \mathrm{~cm}^{-1}\right)$ is hardly visible that indicates a high degree of cross-linking of the polymer.

In the spectrum of BM-GMA besides bands characteristic of esters and epoxides, also very intense signals from maleimide rings $\left(1705,1512 \mathrm{~cm}^{-1}\right)$ can be observed. The homopolymer pDVB in its spectrum has signals characteristic for disubstituted benzenes $\left(820 \mathrm{~cm}^{-1}\right)$ and aliphatic linkages, moreover quite intense bands of vinyl groups (989 and $901 \mathrm{~cm}^{-1}$ ) are clearly visible. Their presence can be associated with the three following situations:

- termination of polymerization occurred as the disproportionation of two macroradicals resulting in reconstruction of double bond in one of the reacting chains

- some monomers have reacted using only one double bond
- or unreacted monomer molecules have been trapped in the polymeric structure.

The latter situations can take place in final stage of polymerization when the viscosity of the polymer increases, hindering the mobility of the macroradicals and addition of next monomers.

After acid modification of the polymers, signals characteristic for epoxides disappeared and bands of hydroxyl groups became visible (3600-3200, 1150-1040 $\left.\mathrm{cm}^{-1}\right)$.

In the spectra of sulphuric acid modified polymers stretching vibrations of $\mathrm{SO}_{2}$ group are located in the ranges 1415-1370 and 1200-1185 $\mathrm{cm}^{-1}$. Primary and secondary alkyl sulfate derivatives give signals in the range of $1315-1050 \mathrm{~cm}^{-1}$. 
Bands representing mono $\left((\mathrm{RO})(\mathrm{HO})_{2} \mathrm{PO}\right)$ and disubstituted $\left((\mathrm{RO})_{2}(\mathrm{HO}) \mathrm{PO}\right)$ organic derivatives of phosphoric acid can be found at about 1250 and $1230 \mathrm{~cm}^{-1}$, respectively. Characteristic vibrations of $\mathrm{P}-\mathrm{OH}$ bonds are visible in the ranges $2700-2560$ and $1040-910 \mathrm{~cm}^{-1}$, while those of $\mathrm{P}=\mathrm{O}$ in the range of $1350-1150 \mathrm{~cm}^{-1}$. The last region is also common to signals of alcohols and esters, therefore interpretation of individual spectral bands in this region may be troublesome (Socrates 2001).

\subsection{Porous structure of the studied materials}

Results of the surface area and porosity measurements are presented in Table 3.

As one can see, the values of the porous structure parameters strongly depended on polymers chemical composition. The highest and the lowest values were observed for $\mathrm{pDVB}$ and BM-GMA, which are respectively apolar and the most polar polymers (Fig. 5). For the DVB-GMA, possessing in its structure both polar functional groups from GMA and apolar units of DVB, $\mathrm{S}_{\mathrm{BET}}$ and $\mathrm{V}_{\mathrm{Tot}}$ take intermediate values.

The dependence of porosity on the chemical structure of the polymer is directly related to the crosslinking density of the polymeric network. This effect is very important because the process of crosslinking promotes the formation of micropores in the polymer structure. In the series of analyzed materials, the density of crosslinking increases with the increase of DVB content. This effect is particularly well visible for DVB-GMA 50:50, DVB-GMA 75:25 and pDVB. The less cross-linked DVB-GMA 50:50 has almost two and a half times smaller specific surface areas $\left(143 \mathrm{~m}^{2} / \mathrm{g}\right)$ than their higher cross-linked counterparts DVB-GMA 75:25 $\left(342 \mathrm{~m}^{2} / \mathrm{g}\right)$ and almost four times smaller than homopolymer pDVB $\left(560 \mathrm{~m}^{2} / \mathrm{g}\right)$. These data are consistent with those reported in the literature (Beneš et al. 2005; Maciejewska et al. 2015).

Figures 6 and 7 present nitrogen sorption isotherms and pore size distribution (PSD) plots of the studied materials which reveal more details about their porosity.

All the materials are mesoporous. The shapes of the adsorption isotherms (type IV-H2) suggest that their porous structure is created by a connected pore system of irregular shape and narrow entrances (Sing 1985). Pore size distributions for the DVB-GMA series are bimodal with a narrow peak at $3.7 \mathrm{~nm}$ and a broader one in the range of 4-12 nm. Worth noticing is also the fact, that PSD curve for DVB-GMA 75:25 is narrower and the peaks are higher than in case of DVB-GMA 50:50, which proves that the pores are more uniform. The highly cross-linked pDVB has additionally some micropores in its structure.

In case of $\mathrm{H}_{2} \mathrm{SO}_{4}$ treated polymers, the first peak is a little shifted to $3.8 \mathrm{~nm}$, while the tops of the other ones are about $6 \mathrm{~nm}$. For $\mathrm{H}_{3} \mathrm{PO}_{4}$ modified materials the apices of second peaks are shifted to higher values, which proves that
Table 3 Porous structure parameters of the synthesized materials

\begin{tabular}{|c|c|c|c|}
\hline Material & $\mathrm{S}_{\mathrm{BET}}\left(\mathrm{m}^{2} / \mathrm{g}\right)$ & $\mathrm{V}_{\text {Tot }}\left(\mathrm{cm}^{3} / \mathrm{g}\right)$ & $\mathrm{W}(\mathrm{nm})$ \\
\hline DVB-GMA 50:50 & 143 & 0.303 & 3.7 and 6.2 \\
\hline DVB-GMA $50: 50+\mathrm{H}_{2} \mathrm{SO}_{4}$ & 189 & 0.305 & 3.8 and 5.5 \\
\hline DVB-GMA $50: 50+\mathrm{H}_{3} \mathrm{PO}_{4}$ & 151 & 0.315 & 3.7 and 6.5 \\
\hline DVB-GMA 75:25 & 342 & 0.458 & 3.7 and 5.5 \\
\hline DVB-GMA $75: 25+\mathrm{H}_{2} \mathrm{SO}_{4}$ & 372 & 0.489 & 3.8 and 6.4 \\
\hline DVB-GMA $75: 25+\mathrm{H}_{3} \mathrm{PO}_{4}$ & 325 & 0.505 & 3.7 and 7.6 \\
\hline BM-GMA 50:50 & 3 & 0.010 & \\
\hline pDVB & 560 & 0.717 & 1.9 and 3.8 and 7.7 \\
\hline
\end{tabular}

Fig. 5 Dependence of the polymers porosity on their chemical composition

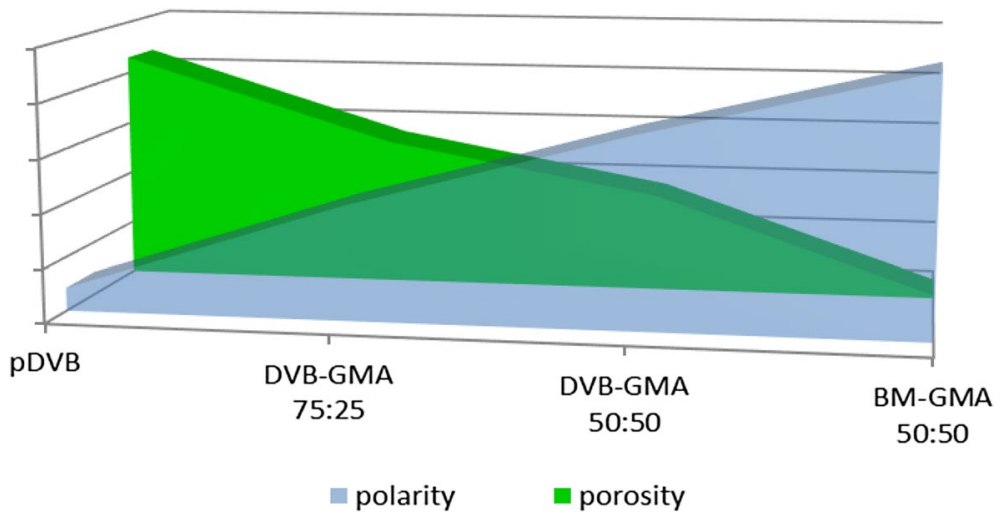


Fig. 6 Nitrogen adsorption-desorption isotherms of the studied polymers

\section{Nitrogen sorption isotherm}

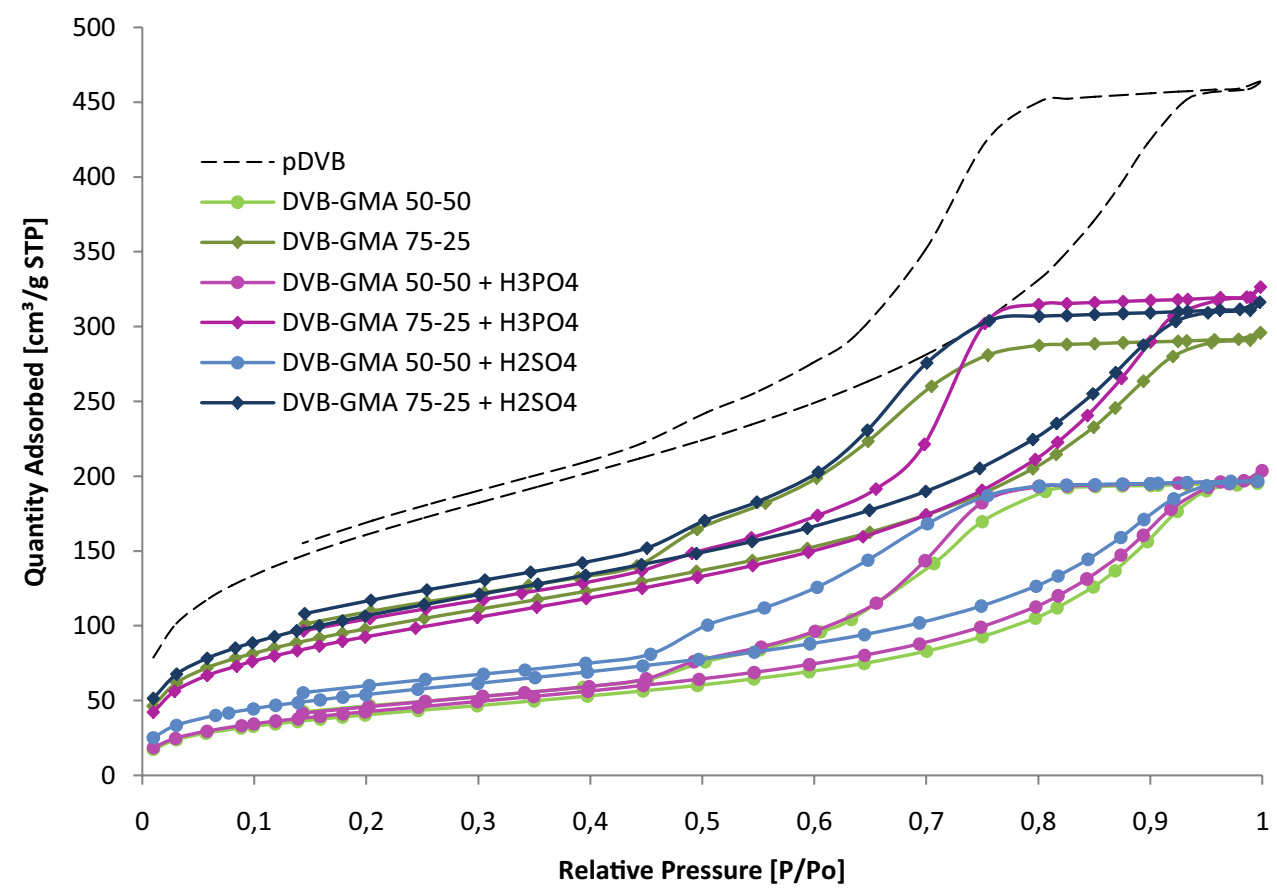

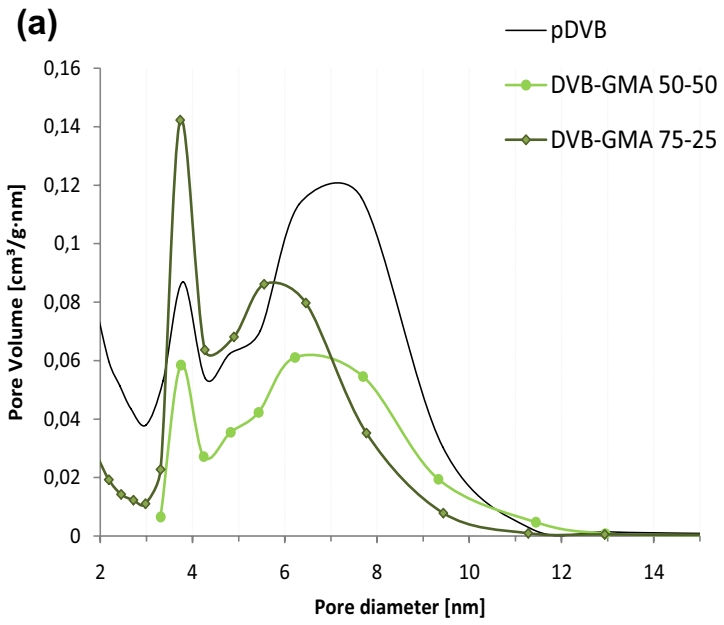

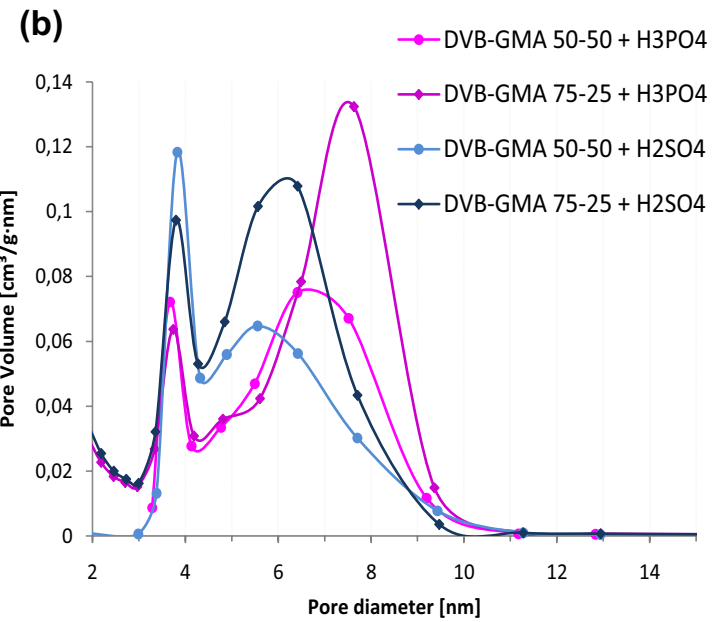

Fig. 7 Pore size distribution curves of a the unmodified polymers and $\mathbf{b} \mathrm{H}_{2} \mathrm{SO}_{4}$ and $\mathrm{H}_{3} \mathrm{PO}_{4}$ treated materials

the modification with sulfuric acid leads to the formation of narrower pores than the phosphoric acid treatment.

\subsection{Thermal properties of the studied polymers}

The results of DSC analyses are shown in Fig. 8. The unmodified DVB-GMA polymers have thermal stability similar to that of $\mathrm{pDVB}$. Their decomposition proceeds in the range of $350-500{ }^{\circ} \mathrm{C}$. And the presence of GMA does not significantly affect thermal properties, especially at temperatures up to $300{ }^{\circ} \mathrm{C}$. In the range of 100 to $250{ }^{\circ} \mathrm{C}$ the process of crosslinking takes place. Its peak is very broad and almost flat which means, that the polymeric structure is highly cross-linked and only a very small number of vinyl bonds did not react. In the DSC curve of BM-GMA two endothermal peaks are visible. The first broad peak, at ca $90{ }^{\circ} \mathrm{C}$ is associated with desorption of moisture, while the second one, the sharp one, at $160{ }^{\circ} \mathrm{C}$ indicates the presence of crystalline BM, which remained entangled and trapped in the polymeric network during polymerization.

After acid modification, the range of decomposition temperatures left unchanged, however thermal destruction 
Fig. 8 DSC of a the unmodified polymers and $\mathbf{b} \mathrm{H}_{2} \mathrm{SO}_{4}$ and $\mathrm{H}_{3} \mathrm{PO}_{4}$ treated materials (a)

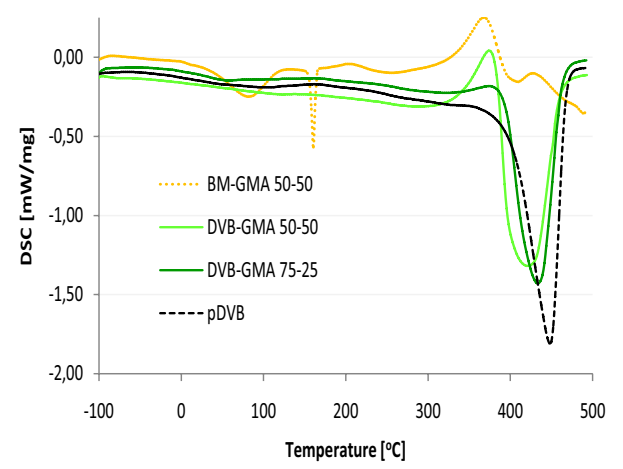

(b)

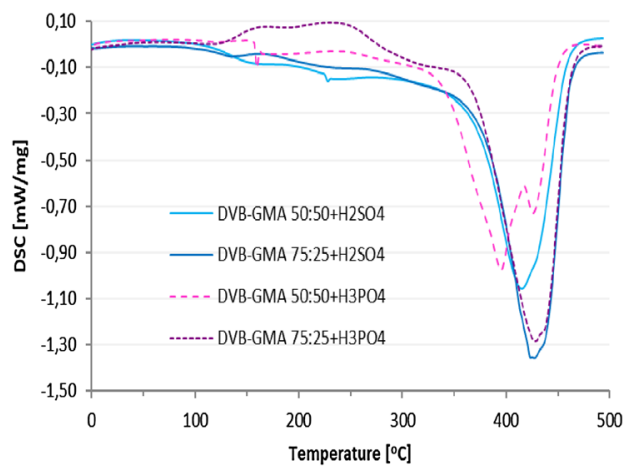

proceeds in two stages. Only in case of DVB-GMA 50:50 $+\mathrm{H}_{3} \mathrm{PO}_{4}$ the processes are well separated and can be observed as two peaks. For other materials the processes take place simultaneously, therefore one unsymmetrical peak is formed.

In the range of $125-175{ }^{\circ} \mathrm{C}$ crosslinking of acid derivatives of DVB-GMA 75:25 occurs. For DVB-GMA 75:25 $+\mathrm{H}_{3} \mathrm{PO}_{4}$ also the additional peak is visible $\left(175-300{ }^{\circ} \mathrm{C}\right)$ which is connected with reactions between phosphate groups and formation of pyrophosphate derivatives (Bielański 1998).
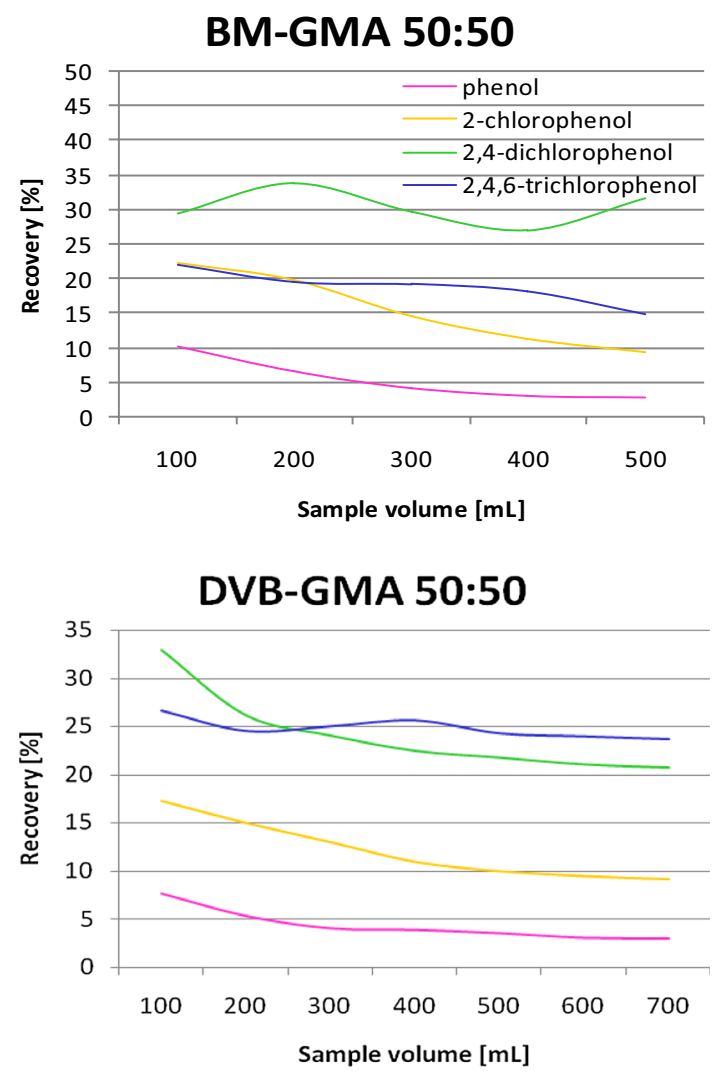

\subsection{The investigation of sorption properties}

The studies of the sorption properties were divided into two parts. At first the sorption ability towards the phenolic compounds were tested, next also the examinations for commonly used pharmaceuticals were performed. The obtained results are presented in Figs. 9 and 10, respectively.

For the unmodified polymers the maximum recoveries reached 30-45\% (for 2-ChP), while the lowest (for phenol) did not exceed $15 \%$. Although the studied materials differ significantly in porosity, their sorption properties are very

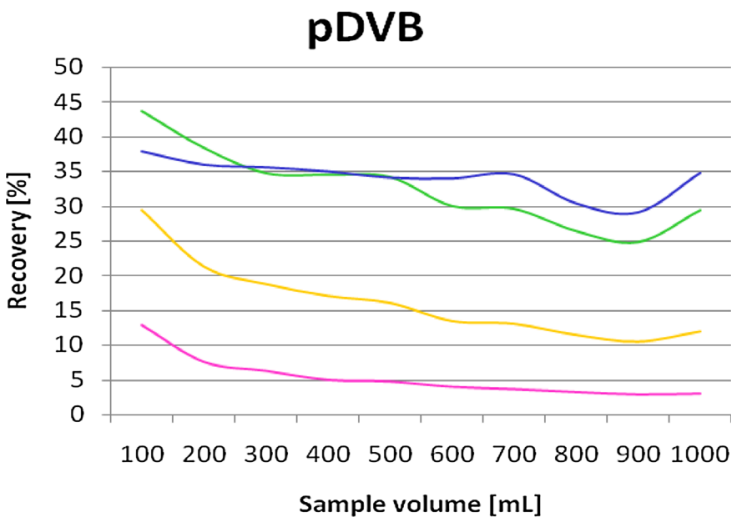

DVB-GMA 75:25

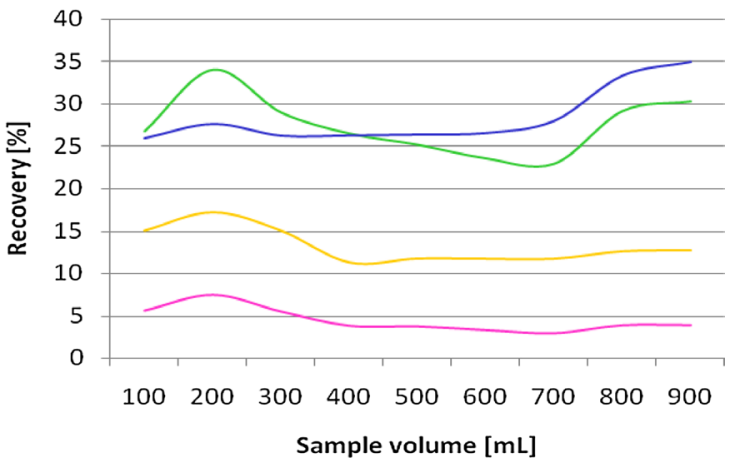

Fig. 9 Recovery curves of the phenolic compounds obtained for the studied polymers 


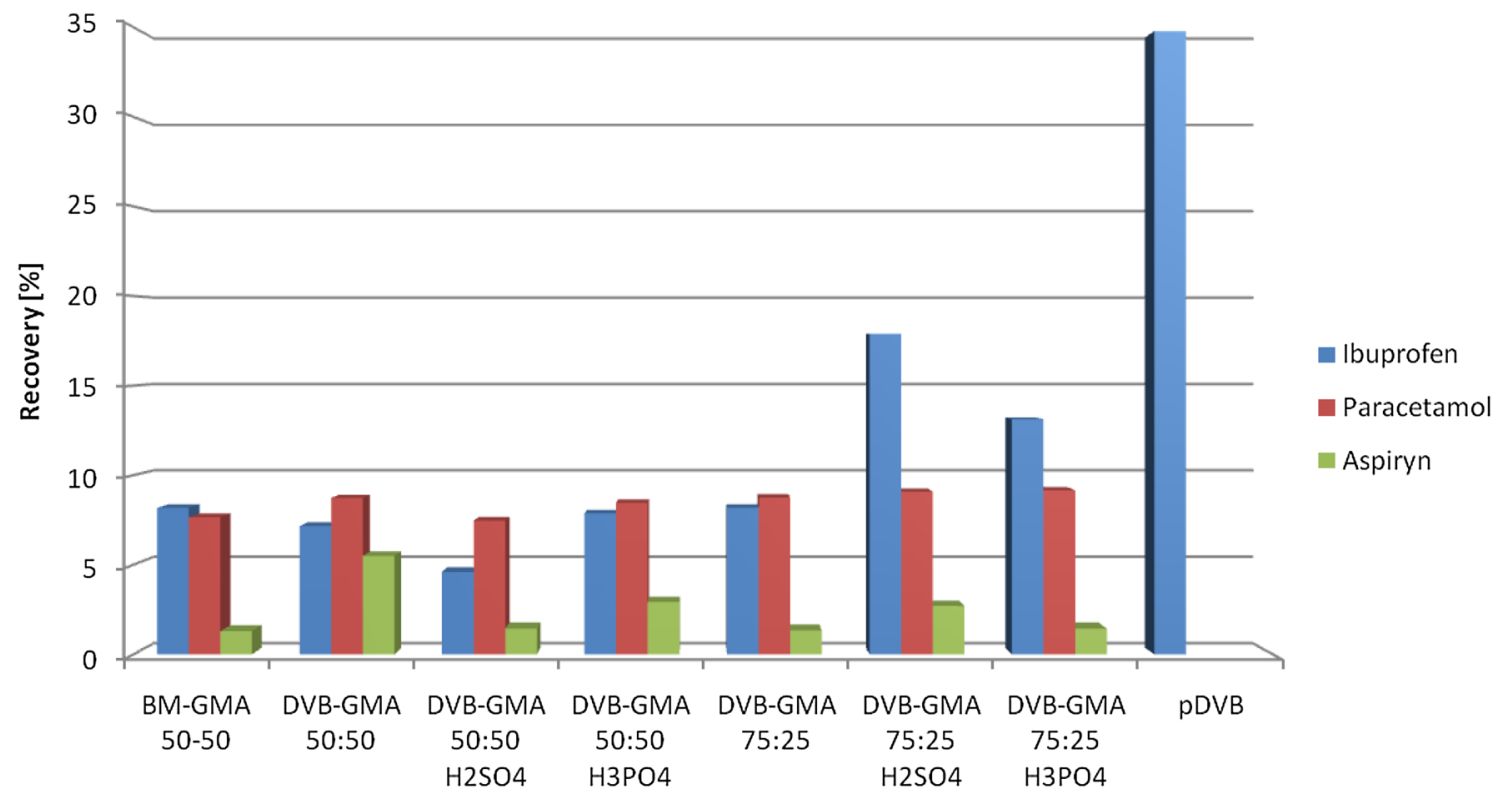

Fig. 10 Recoveries of the pharmaceuticals obtained for the studied polymers

similar. Especially in case of BM-DVB, which has the lowest surface area but the highest polarity, its ability to adsorb the phenols is comparable with that for pDVB. It means the chemical structure of the polymer, and in particular the presence of polar functional groups, has strong impact on its sorption properties towards polar molecules. For the same reason no significant differences in SPE results for DVB-GMA 50:50 and 75:25 were observed, as the reduction of the polarity was balanced by the increase in porosity.

For the acids modified polymers (See Fig. 1s in supplementary material) the recovery results are slightly lower than for unmodified materials, but the impact of the porosity is more pronounced. The phenols sorption on more porous DVB-GMA 75:25 $+\mathrm{H}_{2} \mathrm{SO}_{4}$ or DVB-GMA 75:25 $+\mathrm{H}_{3} \mathrm{PO}_{4}$ reaches almost twice higher values than on respective 50:50 derivatives.

This phenomenon can be explained by the fact that the acidic groups are bulky and due to the steric effect, some pores are hardly accessible for such big adsorbates as aromatic derivatives. In consequence, the process is less efficient and the breakthrough takes place at lower volumes (200-300 mL).

In case of the pharmaceuticals (ibuprofen, paracetamol and aspirin) the results of sorption experiments are more differentiated, which is related to the chemical character of these substances.

Paracetamol is an acetamide derivative of phenol, for this reason their acidity is similar. pKa of paracetamol and phenol are 9.38 and 10.8, respectively. Ibuprofen (pKa 4.91) and aspirin (pKa 3.48) possess more acidic character because of the presence of carboxylic groups.
The sorption of ibuprofen is affected mainly by porosity and less by surface polarity. Therefore, higher recoveries are observed for more porous polymers. However, the most polar but nonporous BM-GMA, also exhibits some sorption ability, resulting from interactions between polymer functional groups and ibuprofen.

In case of paracetamol, acid-base and hydrogen interactions play the key role in the process of sorption. No significant influence of polymer porosity was observed for sorption of this compound.

Recoveries of aspirin do not exceed 5\%. Its acidic character and ability to dissociate do not favor the process of uptake.

\section{Conclusions}

The method of synthesis of porous polymeric microspheres with moderately polar character as well as their modifications with sulphuric or phosphoric acids are reported. The chemical structure of the prepared polymers was confirmed by the elemental and ATR-FTIR analyses as well as titration methods (epoxy and acid numbers). The acid modified polymers gained acidic character and cation exchange properties.

Porosity of the presented materials depended on chemical composition and the degree of crosslinking of the polymers. Also acid modification affected the porous structure. The modification with sulfuric acid led to the formation of pores with average widths 3.8 and $6 \mathrm{~nm}$ while with phosphoric acid the pore sizes were 3.7 and ca $7 \mathrm{~nm}$. 
The prepared materials were tested as potential adsorbents. Their sorption properties towards phenolic compounds (phenol, 2-chlorophenol, 2,4-dichlorophenol and 2,4,6-trichlorophenol) and popular pharmaceuticals-ibuprofen, paracetamol and aspirin were studied using the solid phase extraction method.

The carried out research showed that the process of dynamic sorption of phenols depended on both porous structure and surface chemistry of the studied polymers. And the less polar character of the polymeric surface can be balanced by its higher porosity (and vice versa) to maintain the sorption ability on the same level. In case of pharmaceuticals the dependence of sorption properties on porosity and/or surface chemistry was more diversified and additionally chemical nature of adsorbate had to be taken into account.

Open Access This article is distributed under the terms of the Creative Commons Attribution 4.0 International License (http://creativeco mmons.org/licenses/by/4.0/), which permits unrestricted use, distribution, and reproduction in any medium, provided you give appropriate credit to the original author(s) and the source, provide a link to the Creative Commons license, and indicate if changes were made.

\section{References}

Beneš, M.J., Horák, D., Svec, F.: Methacrylate-based chromatographic media. J. Sep. Sci. 28(15), 1855-1875 (2005)

Bielański, A.: Podstawy Chemii Nieorganicznej (Trzecie). PWN, Warszawa (1998)

Choma, J., Jaroniec, M., Zawiślak, A., Jedynak, K.: Adsorpcyjne wlasciwosci nanoporowatych materialów weglowych otrzymanych z wykorzystaniem matryc krzemionkowych i polimerowych. Ochr. Środ. 31(3), 17-24 (2009)

Fawell, J.K., Hunt, S.: Environmental Toxicology: Organic Pollutants. Wiley, New York (1988)

Gokmen, M.T., Du Prez F.E.: Porous polymer particles-a comprehensive guide to synthesis, characterization, functionalization and applications. Prog. Polym. Sci. 37(3), 365-405 (2012)

Gorzynski Smith, J.: Organic Chemistry, 3rd edn. McGraw-Hill, New York (2011)

Hennion, M.-C.: Solid-phase extraction: method development, sorbents, and coupling with liquid chromatography. J. Chromatogr. A 856(1-2), 3-54 (1999)

Inagaki, M., Park, K.C., Endo, M.: Carbonization under pressure. New Carbon Mater 25, 409-420 (2010)
Keith, L., Telliard, W.: ES\&T Special Report: Priority pollutants: I-a perspective view. Environ. Sci. Technol. 13(4), 416-423 (1979)

Lucas, D., Castellet-Rovira, F., Villagrasa, M., Badia-Fabregat, M., Barceló, D., Vicent, T., Rodríguez-Mozaz, S.: The role of sorption processes in the removal of pharmaceuticals by fungal treatment of wastewater. Sci. Total Environ. 610-611, 1147-1153 (2018)

Maciejewska, M.: Synthesis and characterization of textural and thermal properties of polymer monoliths. J. Therm. Anal. Calorim. 121(3), 1333-1343 (2015a)

Maciejewska, M.: Characterization of thermal properties of porous microspheres bearing pyrrolidone units. J. Therm. Anal. Calorim. 119(2), 1147-1155 (2015b)

Maciejewska, M., Kołodyńska, D.: Synthesis and characterization of porous microspheres bearing pyrrolidone units. Mater. Chem. Phys. 149-150(2), 43-50 (2015)

Namieśnik, J.W.: Chrzanowski,: Nowe horyzonty i wyzwania w analityce i monitoringu środowiskowym. CEEAM, Gdańsk (2003)

Parlament Europejski: DECYZJA NR 2455/2001/WE z dnia 20 listopada 2001 r. Dziennik Urzędowy Wspólnot Europejskich, L 331/1(15/t. 6), 358-362 (2001)

Parlament Europejski: ROZPORZĄDZENIE (WE) NR 166/2006 PARLAMENTU EUROPEJSKIEGO I RADY z dnia 18 stycznia 2006 r. Dziennik Urzędowy Unii Europejskiej I, L33, 1-17 (2006)

Podkościelna, B., Sobiesiak, M., Zhao, Y., Gawdzik, B., Sevastyanova, O.: Preparation of lignin-containing porous microspheres through the copolymerization of lignin acrylate derivatives with styrene and divinylbenzene. Holzforschung 69(6), 49-56 (2015)

Simpson, N.J.K.: Solid-Phase Extraction-Principles. Techniques and Applications. Marcel Dekker. Inc, New York (2000)

Sing, K.S.W.: Reporting physisorption data for gas/solid systems with special reference to the determination of surface area and porosity. Pure Appl. Chem. 57(4), 603-619 (1985)

Sobiesiak, M.: Bead-shaped porous polymers containing bismaleimide- their physico-chemical characteristics and sorption properties towards chlorophenols. Polish J. Appl. Chem. Lv(1), 25-32 (2011)

Sobiesiak, M., Podkoscielna, B.: Preparation and characterization of porous DVB copolymers and their applicability for adsorption (solid-phase extraction) of phenol compounds. Appl. Surf. Sci. 257(4), 1222-1227 (2010)

Socrates, G.: Infrared and Raman Characteristic Group Frequencies: Tables and Charts, 3rd edn. Wiley, Chichester (2001)

The European Parliament.: Decision No 2455/2001/EC of the European Parliament and of the Council of 20 November 2001. Official Journal of the European Communities, L 331, 1-5 (2001)

WHO.: International Standards for Drinking-Water, 3rd edn. World Health Organization, Geneva (1971)

Xu, L.-Y., Shi, Z.-G., Feng, Y.-Q.: Preparation of a carbon monolith with bimodal perfusion pores. Microporous Mesoporous Mater. 115(3), 618-623 (2008) 